\title{
Evaluation of global ocean tide models based on tidal gravity observations in China
}

\author{
Hongbo Tan ${ }^{\text {a, b, * }}$, Olivier Francis ${ }^{c}$, Guiju Wu ${ }^{\text {b }}$, Guangliang Yang ${ }^{\mathrm{b}}$, Jiapei Wang ${ }^{\mathrm{b}}$, \\ Xiaotong Zhang ${ }^{b}$, Jinshui Huang ${ }^{\text {a }}$, Chongyang Shen ${ }^{b}$ \\ a School of Earth and Space Sciences, University of Science and Technology of China, Hefei, 230026, China \\ ${ }^{\mathrm{b}}$ Key Laboratory of Earthquake Geodesy, Institute of Seismology, China Earthquake Administration, Wuhan, 430071, China

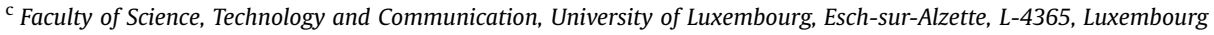

\section{A R T I C L E I N F O}

\section{Article history:}

Received 19 January 2021

Accepted 2 August 2021

Available online 13 August 2021

\section{Keywords:}

Gravity signals

Ocean tidal loading

Global ocean tide models

gPhone gravimeter

\begin{abstract}
A B S T R A C T
Previous studies show that the calculated loading effects from global ocean tide models do not match actual measurements of gravity attraction and loading effects in Southeast Asia. In this paper, taking advantage of a unique network of gravity tidal stations all over the Chinese mainland, we compare the observed and modeled tidal loading effects on the basis of the most recent global ocean tide models. The results show that the average efficiencies of the ocean tidal loading correction for $\mathrm{O}_{1}, \mathrm{~K}_{1}, \mathrm{M}_{2}$ are $77 \%, 73 \%$ and $59 \%$, respectively. The loading correction efficiencies using recent ocean tidal models are better than the 40 years old Schwiderskis model at coastal stations, but relative worse at stations far from ocean.

๑) 2021 Editorial office of Geodesy and Geodynamics. Publishing services by Elsevier B.V. on behalf of KeAi Communications Co. Ltd. This is an open access article under the CC BY-NC-ND license (http:// creativecommons.org/licenses/by-nc-nd/4.0/).
\end{abstract}

\section{Introduction}

Solid Earth is affected by tidal cycles triggered by the gravity attraction of the celestial bodies, in which the main contributions are from the Moon and Sun. The tides of the solid Earth, so-called body tides, are precisely modelled assuming that the Earth is an elastic body. However, about $70 \%$ of the Earth is covered with seawater which is also affected by tidal forces. Non-astronomical factors such as local depth of the water, ocean-floor topography, configuration of the coastlines, and other hydrographic and meteorological influences significantly complicate the ocean tides models. The periodic movements of seawater are responsible for gravity loading effects at the Earth's surface. These include direct effect (due to the direct gravity attraction of seawater mass) and

\footnotetext{
* Corresponding author. School of Earth and Space Sciences, University of Science and Technology of China, Hefei, 230026, China.

E-mail address: thbhong@163.com (H. Tan).

Peer review under responsibility of Institute of Seismology, China Earthquake Administration.
}

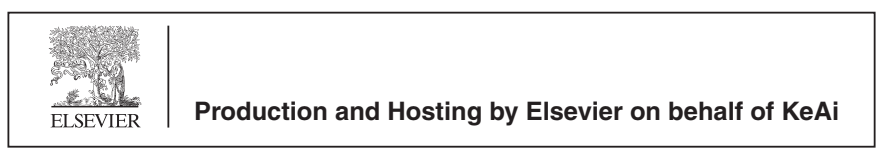

indirect effect (due to the deformation of the Earth's crust caused by ocean load and the disturbed gravity field caused by the redistribution of the internal mass of the Earth) [1,2]. In the coastal areas, the ocean tidal loading (OTL) effects are more pronounced. The gravity loading can reach up to $10 \%$ of the earth tide, $90 \%$ for tilt, and $25 \%$ for strain. Even deep in the interior land, the effects can reach a few percent of the solid earth [1,3]. So, it is a non-negligible part in tidal analysis.

In the early 20th century in Europe, researchers found that the tidal factors between the South-to-North and West-to-East direction were inconsistent at one station, as well as the coastal and inland stations. At that time, they suspected it was caused by the influence of ocean tides [4]. In the 1960s, Munk [5] introduced the concept of the load Love numbers. With the improvement of Longman's [6] calculation method, 1000-order load Love numbers were calculated by Farrell [1]. The gravity, displacement, tilt and strain loading Green's functions were also computed that made possible to quantitatively study the ocean load. The first accurate and precise global ocean tidal model (OTM) was proposed by Schwiderski (SCHW) $[7,8]$ based on the oceanic dynamic equation including a large number of tide gauge observations. Global OTL effects were computed by 0 . Francis [3] using the convolution method of Farrell [1]. With the development of satellite altimetry technology and the accumulation of data, a series of high precision and spatial resolution OTMs have been published, such as FES2014, 
DTU10, TPXO8, TPXO9, EOT11, HAMTIDE, NAO.99b [9-15]. The OTL precision depends on the OTM precision. Ocean tides are affected by the coastline configuration and submarine topography, especially in the bays, trenches and shallow sea. With the uncertainty of water depth, friction and viscosity coefficients at seafloor, the precision of the OTM in shallow water areas is still an issue [16]. Consequently, continental observations such as gravity and GPS are helpful to evaluate and even improve the OTMs [17].

Since 2007, a network of permanent relative gravity stations has been established in the framework of two projects: the Crustal Movement Observation Network of China (CMONOC) and the China Digital Earthquake Observation Network (CDEON) (see Fig. 1) [18]. Today, there are 78 stations with 84 gravimeters. More than 60 of them are equipped with gPhone or superconducting gravimeters (SG) with time sampling of $1 \mathrm{~Hz}$. The long time series provide precise and stable tidal data that offer the opportunity to validate, assess the precision or even improve OTMs. In this paper, tidal parameters of each station were extracted using the harmonic analysis method after a careful editing of the raw data. The efficiencies of OTL correction using different OTMs are compared and discussed to select reference OTMs for China.

\section{Ocean loading modelling}

The gravity acceleration due to the ocean tides direct attraction and loading is given by [1]:

$I(\varphi, \lambda)=\rho_{w} \iint_{\Omega} G(\alpha) h\left(\varphi^{\prime}, \lambda^{\prime}\right) \mathrm{d} s^{\prime}$

where $\varphi$ and $\lambda$ denote latitude and longitude of the point of interest, $\rho_{w}$ the mean density of seawater, $\Omega$ the domain of integration, $h\left(\varphi^{\prime}, \lambda^{\prime}\right)$ the elevation of the sea surface in-phase or in-quadrature for a given tidal wave on the surface area $\mathrm{d} s^{\prime}$, and the angle $\alpha$ is calculated by

$\cos \alpha=\sin \varphi \sin \varphi^{\prime}+\cos \varphi \cos \varphi^{\prime} \cos \left(\lambda-\lambda^{\prime}\right)$

$G(\alpha)$ is the Green's Function expressed by

$G(\alpha)=\frac{g}{m_{e}} \sum_{n=0}^{\infty}\left[n+2 h_{n}^{\prime}-n(n+1) k_{n}^{\prime}\right] P_{n}(\cos \alpha)$

in which $g$ is the gravity acceleration, $m_{e}$ the total mass of the Earth, $h_{n}^{\prime}, k_{n}^{\prime}$ the load Love numbers, and $P_{n}$ the Legendre polynomials.

For the numerical evaluation, the ocean is usually divided into a set of cells, and the Green's function tabulated by Farrell [1] is interpolated for the intermediate values of $\alpha$ using cubic splines. Then the total response can be written as

$I(\varphi, \lambda)=\rho_{w} \sum_{i=0}^{N} G\left(\alpha_{i}\right) h_{i}\left(\varphi^{\prime}, \lambda^{\prime}\right) \mathrm{d} s_{i}^{\prime}$

where $N$ is the total number of oceanic cells of the OTM.

\section{Gravity data and preprocessing}

From more than 60 gravity stations, we selected 35 of them (Fig. 1). The others were not considered due to bad data quality, insufficient data or time stamps issues. All stations are equipped with gPhones or SGs with data length ranging from 1 to 3 years (Table 1). Most of the stations are located in the east and south of China (Fig. 1). Eleven stations are located along the ocean coasts. The closest station to the ocean is XiaMen (XM) station just less than $1 \mathrm{~km}$ to the nearest sea, while the farthermost station is ALeTai (ALT) at a distance of more than $2500 \mathrm{~km}$.

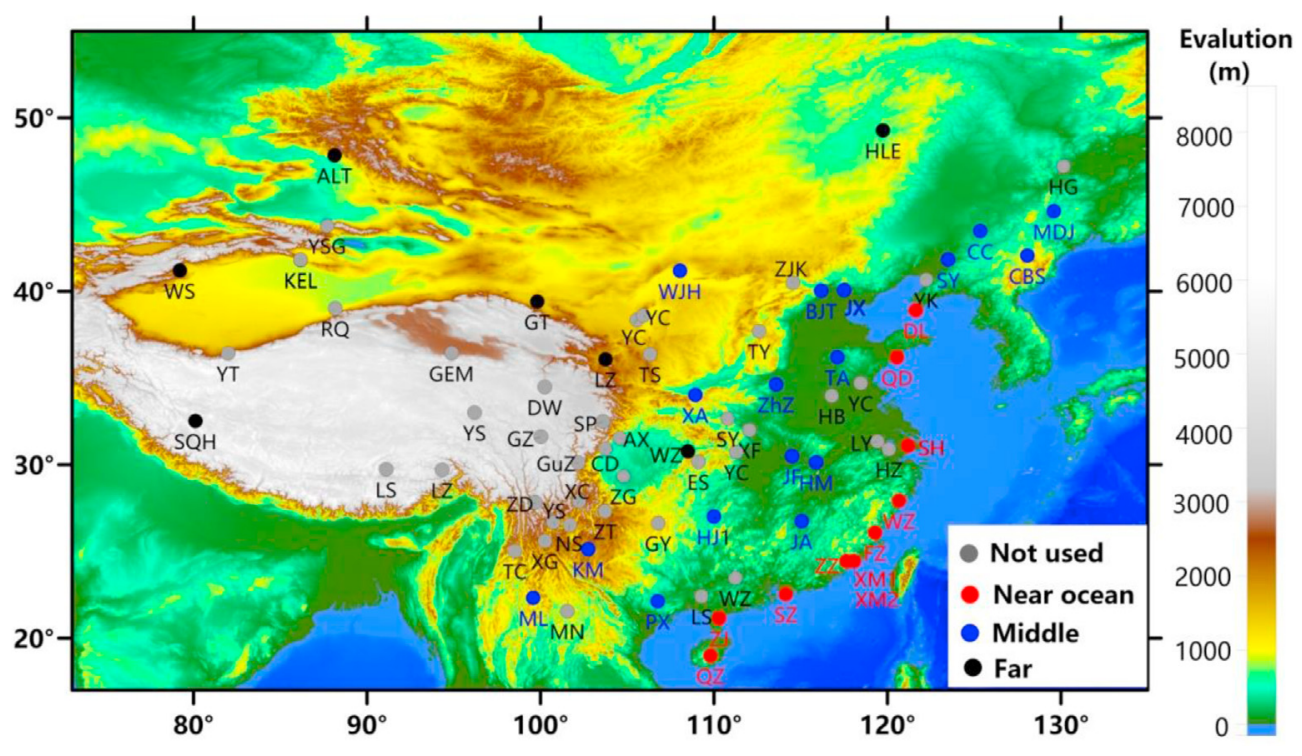

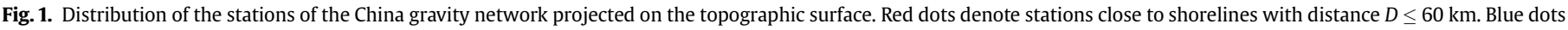

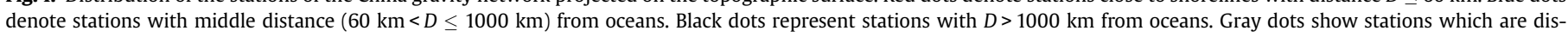

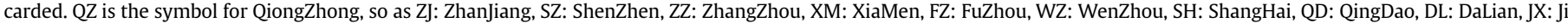

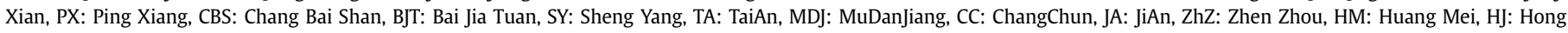

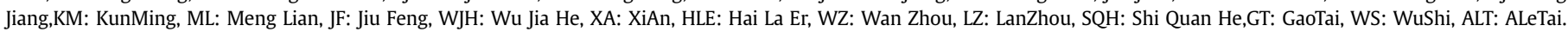


Table 1

Length of the data series, atmospheric pressure admittance factor and precision of the gravity time series included in this paper.

\begin{tabular}{|c|c|c|c|c|}
\hline No. & Station & $\begin{array}{l}\text { Observation period } \\
\text { (Year-Month-Day) }\end{array}$ & $\begin{array}{l}\text { Atmospheric } \\
\text { gravity } \\
\text { admittance } \\
\left(10^{-8} \mathrm{~m} \cdot \mathrm{s}^{-2} / \mathrm{hPa}\right)\end{array}$ & $\begin{array}{l}\text { Standard } \\
\text { deviation } \\
\text { of tidal } \\
\text { parameters } \\
\left(10^{-8} \mathrm{~m} \cdot \mathrm{s}^{-2}\right)\end{array}$ \\
\hline 1 & $\mathrm{QZ}$ & $20090211-20130114$ & $-0.364 \pm 0.007$ & 0.613 \\
\hline 2 & ZJ & 20101203-20120229 & $-0.390 \pm 0.038$ & 1.772 \\
\hline 3 & SZ & $20111103-20121103$ & $-0.399 \pm 0.014$ & 0.657 \\
\hline 4 & $\mathrm{ZZ}$ & 20091201-20130115 & $-0.290 \pm 0.009$ & 0.851 \\
\hline 5 & XM1 & 20101019-20111107 & $-0.331 \pm 0.024$ & 1.001 \\
\hline 6 & XM2 & $20101019-20120229$ & $-0.298 \pm 0.021$ & 1.140 \\
\hline 7 & $\mathrm{FZ}$ & $20150101-20161231$ & $-0.229 \pm 0.004$ & 0.324 \\
\hline 8 & WZ & $20150101-20161231$ & $-0.360 \pm 0.009$ & 0.367 \\
\hline 9 & SH & $20150101-20161231$ & $-0.287 \pm 0.009$ & 0.806 \\
\hline 10 & QD & 20101130-20120911 & $-0.303 \pm 0.007$ & 0.527 \\
\hline 11 & DL & $20150101-20161231$ & $-0.345 \pm 0.003$ & 0.328 \\
\hline 12 & JX & 20110525-20120229 & $-0.324 \pm 0.005$ & 0.281 \\
\hline 13 & PX & $20150101-20161231$ & $-0.254 \pm 0.004$ & 0.267 \\
\hline 14 & CBS & 20090310-20110416 & $-0.309 \pm 0.006$ & 0.575 \\
\hline 15 & BJT & 20080101-20120411 & $-0.339 \pm 0.002$ & 0.293 \\
\hline 16 & SY & 20100821-20120301 & $-0.363 \pm 0.002$ & 0.173 \\
\hline 17 & TA & 20090201-20130114 & $-0.339 \pm 0.002$ & 0.351 \\
\hline 18 & MDJ & 20090202-20130113 & $-0.346 \pm 0.003$ & 0.633 \\
\hline 19 & $\mathrm{CC}$ & 20110526-20120229 & $-0.388 \pm 0.005$ & 0.280 \\
\hline 20 & JA & $20110315-20120229$ & $-0.305 \pm 0.007$ & 0.305 \\
\hline 21 & ZhZ & 20080919-20130114 & $-0.337 \pm 0.001$ & 0.217 \\
\hline 22 & HM & 20080930-20121231 & $-0.341 \pm 0.002$ & 0.455 \\
\hline 23 & $\mathrm{HJ}$ & 20101019-20121008 & $-0.410 \pm 0.006$ & 0.481 \\
\hline 24 & KM & 20111231-20130419 & $-0.323 \pm 0.004$ & 0.217 \\
\hline 25 & ML & 20150101-20161231 & $-0.379 \pm 0.003$ & 0.216 \\
\hline 26 & $\mathrm{JF}$ & 20090216-20111218 & $-0.324 \pm 0.001$ & 0.077 \\
\hline 27 & WJH & 20090224-20130109 & $-0.302 \pm 0.001$ & 0.146 \\
\hline 28 & $\mathrm{XA}$ & $20090316-20130115$ & $-0.330 \pm 0.002$ & 0.127 \\
\hline 29 & HLE & 20090101-20110308 & $-0.376 \pm 0.002$ & 0.255 \\
\hline 30 & WZ & 20101107-20120101 & $-0.339 \pm 0.006$ & 0.317 \\
\hline 31 & $\mathrm{LZ}$ & 20090219-20130115 & $-0.335 \pm 0.001$ & 0.188 \\
\hline 32 & $\mathrm{SQH}$ & 20090917-20110530 & $-0.354 \pm 0.001$ & 0.082 \\
\hline 33 & GT & 20090304-20111216 & $-0.381 \pm 0.001$ & 0.166 \\
\hline 34 & WS & $20090131-20120812$ & $-0.381 \pm 0.002$ & 0.309 \\
\hline 35 & ALT & 20101029-20120229 & $-0.397 \pm 0.004$ & 0.180 \\
\hline
\end{tabular}

We us Tsoft [19], a specifically designed software, for earth tide series pre-processing recommended by the International Center for Earth's Tides (ICET). An interactive remove-restore approach allows us editing the gravity data for gaps, steps and spikes on the 1-min sampling time series. The clean data are then decimated to hourly values using a low-pass digital filter. Those are finally used to estimate the observed tidal parameters with the Earth Tide Analysis and Prediction Program System ET34-X-V72 [20,21]. A band-pass filter is applied on the pre-processed hourly data to eliminate the instrumental drift. Then the diurnal, semi-diurnal and one-thirddiurnal tidal constituents are separated according to the different characteristics of angular frequency of the tide.

\section{Ocean loading correction}

The periodic variation of seawater is considered as the synthetic result of the periodic motion of each tidal wave. So the tidal height $h(t)$ can be expressed as

$h(t)=\sum_{i=1}^{N} A_{i} \cos \left(\omega_{i} t+\varphi_{i}\right)$

where the tidal parameters of $A_{i}, \omega_{i}$ and $\varphi_{i}$ are the amplitude, frequency and initial phase of the $i^{\text {th }}$ tidal constituent. There are 11 major tidal constituents, including $\mathrm{M}_{2}, \mathrm{~S}_{2}, \mathrm{~N}_{2}, \mathrm{~K}_{2}, \mathrm{~K}_{1}, \mathrm{O}_{1}, \mathrm{P}_{1}, \mathrm{Q}_{1}, \mathrm{M}_{\mathrm{f}}$, $\mathrm{M}_{\mathrm{m}}$ and $\mathrm{S}_{\mathrm{sa}}$. For each tidal constituent, we define $\boldsymbol{M}(M, 0)$ as the vector of the modelled gravity solid Earth tide, $\boldsymbol{A}(A, \alpha)$ as the vector of the measured gravity tide, $\boldsymbol{L}(L, \lambda)$ as the OTL vector. The relationship between the first residual vector $\boldsymbol{B}(B, \beta)$ and the final residual vector $\boldsymbol{X}(X, \chi)$ after OTL correction are defined as (see Fig. 2 ):

$\boldsymbol{X}(X, \chi)=\boldsymbol{B}(B, \beta)-\boldsymbol{L}(L, \lambda)$

$\boldsymbol{B}(B, \beta)=\boldsymbol{A}(A, \alpha)-\boldsymbol{M}(M, 0)$

where, $M, A, L, B, X$ are the amplitudes, $\lambda, \chi, \beta$ are the phases of their corresponding vectors respectively. $\alpha$ is the phase lag between the observed gravity vector and the solid Earth Tide elastic model.

OTLs can be computed from Ocean Tide Loading Provider (http://holt.oso.chalmers.se/loading/) [22,23]. Amplitudes and phases of the 11 main constituents for more than 20 OTMs are offered from which vectors $\boldsymbol{B}$ and $\boldsymbol{X}$ are calculated.

\section{Results}

In this section, the results for all the 35 stations are presented. The stations are classified according to the distance from the nearest sea.

\subsection{For all stations}

Fig. 3a shows the Root-Mean-Squares (RMS) of the observational errors $\left(M_{0}\right)$ for each station. It reflects the station environmental conditions (background noise, environmental change, ... ) and the data uncertainties. They vary between 0.08 and $1.77 \mu \mathrm{gal}$ $\left(10^{-8} \mathrm{~m} / \mathrm{s}^{2}\right)$. The average errors as a function of the distance from the sea are $0.76,0.30$ and $0.21 \mu$ gal for near, middle and far stations, respectively. Obviously, the observational errors of the 11 stations which are the closest to the sea are much bigger than the others. The total final gravity residuals were defined as

$T x=\sqrt{\sum_{i=1}^{N} X_{i}^{2}}, N=8$

where $X_{i}$ is the final residuals form equation (6) and $i$ denotes one of the 8 major constituents $\left(M_{2}, S_{2}, N_{2}, K_{2}, K_{1}, O_{1}, P_{1}, Q_{1}\right)$. It reflects the absolute efficiency of solid earth tide and OTL correction. The range of $T x$ is $0.14-3.45 \mu$ gal using the best OTM. The ratios between $T x$ and $M_{0}$ (Fig. $3 \mathrm{~b}$ ) indicate that there are still tidal signals

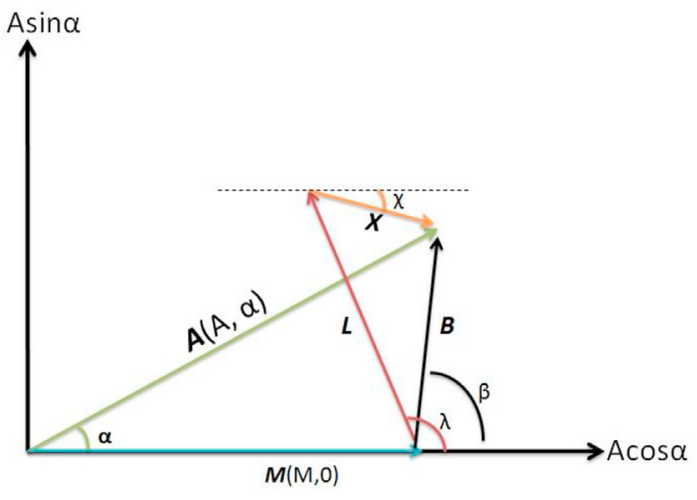

Fig. 2. The relation between observation, model and OTL vectors. 


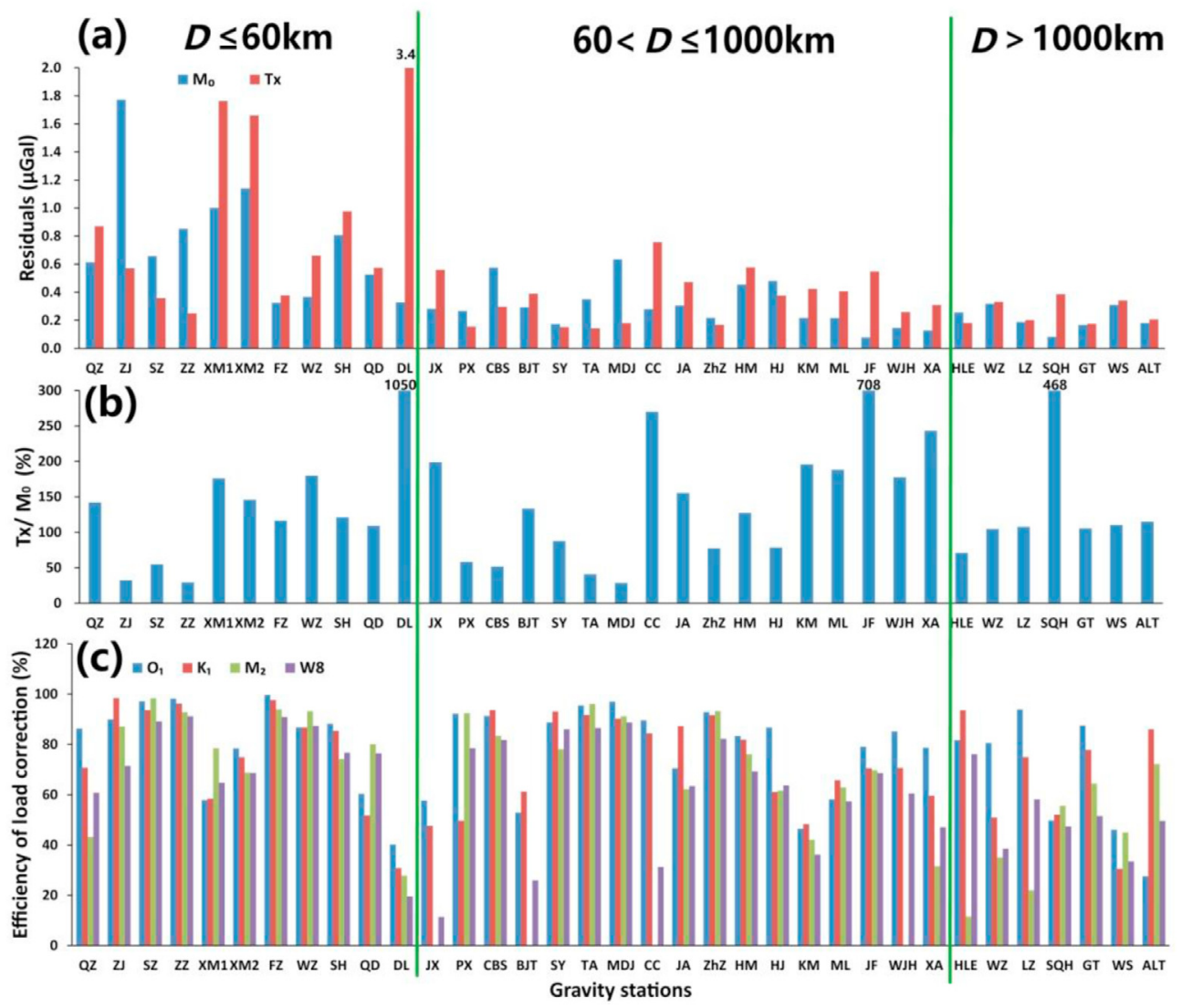

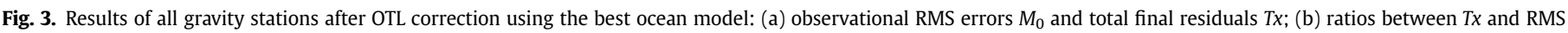

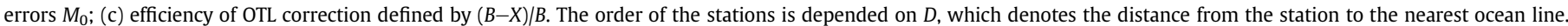

in the residuals at a significant level: the leftover tidal signals are above the observational errors. 24 of the 35 stations have a ratio higher than 100\%. An extreme example is the DaLian (DL) station, for which the ratio is above $1000 \%$. Fig. $3 \mathrm{c}$ also gives the relative efficiency of the OTL correction defined as $(B-X) / B$ and

$R E=\frac{\sqrt{\sum_{i=1}^{N} B_{i}^{2}}-\sqrt{\sum_{i=1}^{N} X_{i}^{2}}}{\sqrt{\sum_{i=1}^{N} B_{i}^{2}}}, \mathrm{~N}=8$

for $O_{1}, K_{1}, M_{2}$ and $W 8$ (the 8 tidal constituents of $M_{2}, S_{2}, N_{2}, K_{2}, K_{1}, O_{1}$, $P_{1}, Q_{1}$ ). The average efficiency for $O_{1}$ is $77 \%$, while $73 \%, 59 \%$ and $62 \%$ for $K_{1}, M_{2}$ and $W 8$, respectively. So, $O_{1}$ shows the largest tides reduction compared to $K_{1}$ and $M_{2}$. More specifically, the OTL is ineffective at Ji Xian (JX), Bai Jia Tuan (BJT), ChangChun (CC), and Wu Jia He (WJH) stations.

The occurrence frequencies of the best OTM for each tidal constituent are plotted in Fig. 4a: 3 stations with two best OTMs for $M_{2}$, and 2 stations for $W 8$. Overall, FES2014b provides the best corrections for $O_{1}$ at 12 stations, while SCHW provides the best for $K_{1}, M_{2}$ and $W 8$ at 12, 8 and 9 stations. On the other hand, DTU10 performs well for W8. Interestingly, the gravity loadings obtained with SCHW are always different from the other models. In fact, the SCHW model is the best OTM for the Chinese mainland. The efficiency of OTL correction is displayed in Fig. 4b. There are 21 stations of which the correction efficiency reaches up to $80 \%$ for $O_{1}$ while
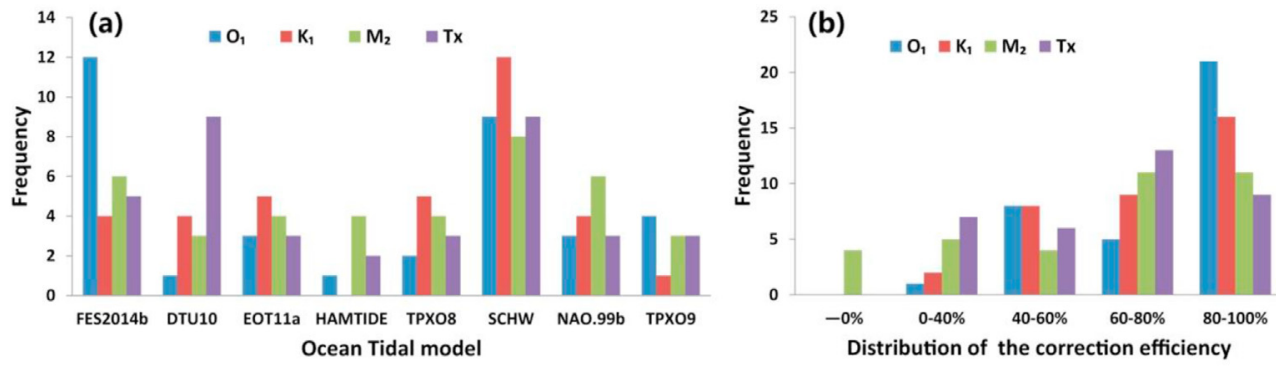

Fig. 4. Statistical results for all gravity stations: (a) the frequency of the best OTM; (b) the distribution of the correction efficiencies. 
using the best OTM. The correction efficiencies are higher than $60 \%$ for $K_{1}, M_{2}$ and $W 8$ at 25,22 and 22 stations respectively.

\subsection{Coastal stations}

There are 11 stations close to the South and East China Sea with a distance less than $60 \mathrm{~km}$. The observational errors $\left(M_{0}\right)$ and total final residuals $(T x)$ are $0.32-1.77$ and $0.25-3.45 \mu$ gal (Fig. 3a). Their ratios show that only 3 of them are less than 100\%. The statistical results for the best OTM of the main ocean tides $O_{1}, K_{1}$, $\mathrm{M}_{2}$ and $\mathrm{W} 8$ are displayed in Fig. 5a. There is not an obvious best OTM for the stations in coastal areas. DTU10 is the best OTM for $K_{1}$ and $\mathrm{W} 8$, while NAO.99b is the best on $M_{2}$. In summary, the DTU10, EOT11a and TPXO8 models perform slightly better than the others (see Fig. 5a). We see an efficiency of the OTL correction higher than $60 \%$ at most coastal stations. However, the total final residuals ( $T x$ ) are much bigger than the observational errors (for an example, $T x=3.4 \mu$ gal and $M_{0}=0.33 \mu$ gal at DaLian station). It indicates that there are still un-modeled OTL signals in the residuals.

\subsection{Stations with middle distance from the ocean}

17 stations are located at a distance between 60 and $1000 \mathrm{~km}$ from the ocean, including a superconducting gravimeter at Jiu Feng (JF) station. The observation errors $\left(M_{0}\right)$ and total final residuals ( $T x$ ) are 0.077 and $0.55 \mu$ gal, while the ranges for the other 16 stations are $0.13-0.63$ and $0.14-0.76 \mu$ gal (Fig. $3 a$ ). Ratio is less than $100 \%$ for only 7 stations. The statistical results of the best OTM for the main ocean tides of $O_{1}, K_{1}, M_{2}$ and W8 are shown in Fig. $6 \mathrm{a}$. At a middle distance, FES2014b is best on $O_{1}$, but obviously, SCHW is the best OTM. For most of the stations, the efficiencies of OTL correction are larger than $60 \%$.

\subsection{Stations far from ocean}

There are 7 stations located far from the ocean at a minimum distance of $1000 \mathrm{~km}$. The range of the observation errors $\left(M_{0}\right)$ and total residuals (Tx) are $0.082-0.32$ and $0.18-0.34 \mu$ gal (Fig. 3a). Their ratios show that only one of them is smaller than $100 \%$. The statistical result in Fig. 7a shows that FES2014b and SCHW model
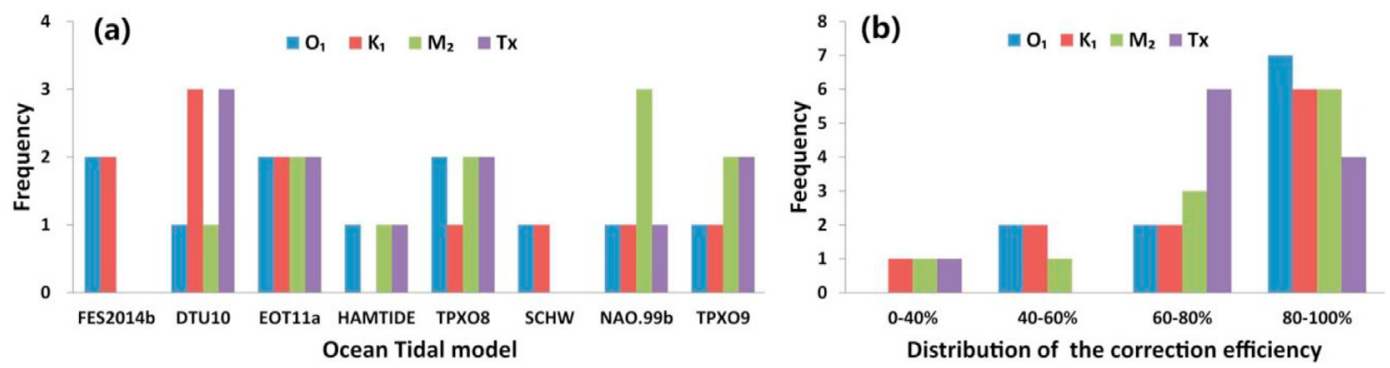

Fig. 5. Statistical results for near ocean stations ( $\leq 60 \mathrm{~km}$ ): (a) the frequency of the best OTM; (b) the distribution of the correction efficiencies.
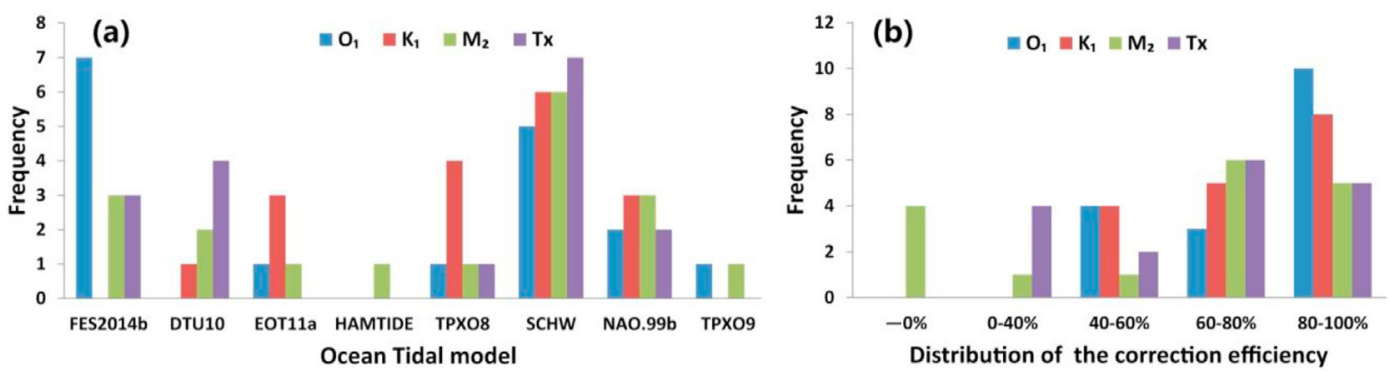

Fig. 6. Statistical results for middle distance stations $(60<D \leq 1000 \mathrm{~km})$ : (a) the frequency of the best OTM; (b) the distribution of the correction efficiencies.
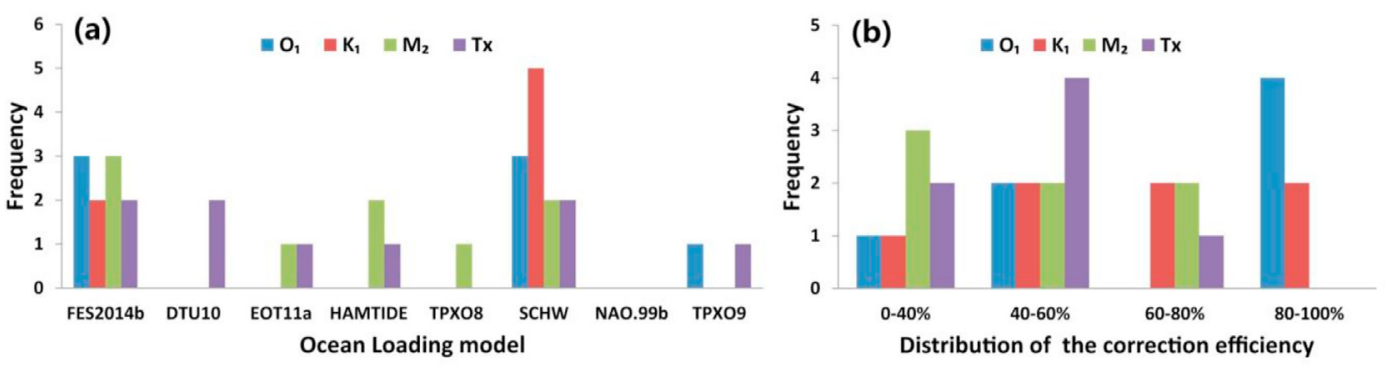

Fig. 7. Statistical results for far stations $(D>1000 \mathrm{~km})$ : (a) the frequency of the best OTM; (b) the distribution of the correction efficiencies. 
are the best models. But the correction efficiency is worse than the near and middle stations from the seas. This could be attributed to the smaller signal-to-noise ratio.

\section{Discussion}

The distribution of the best OTM for $\mathrm{O}_{1}$ is shown in Fig. 8a. The FES2014b is the best one for 12 stations, which are mainly located at the northeast and southeast of China. For the stations closer to the sea, EOT11a is the best OTM for the south coast stations. FES2014b is the best OTM in the east regions while SCHW is the best one in the north of Chinese coast. The situation is different for $K_{1}$ : SCHW performs well at 12 stations with most of which located far from the ocean except DaLian (Fig. 8b). For $M_{2}$, SCHW is the best one at 8 stations, including the farthest station AaLe Tai, and 5 of them are located at southwest and north of China. Considering the main 8 tidal constituents, SCHW is the best for 9 stations with a distribution similar with $M_{2}$, and DTU10 is the best for 9 stations. Overall, it is not easy to decide which OTM performs the best. However, SCHW is generally better than the other OTMs except along the coastal areas. DTU10 is the next, and HAMTIDE performs the worst in China. The resolution of SCHW is $1^{\circ} \times 1^{\circ}$, and $1^{\circ} / 8 \times 1^{\circ} / 8$ for DTU10, $1^{\circ} / 16 \times 1^{\circ} / 16$ for FES2014b could explain why SCHW is less performing close to the sea. Although new models (such as FES2014, DTU10 and NAO.99b) use satellite altimetry, more accurate ocean bathymetry data and even a regional OTM around Japan, with higher resolution, they do not outclass SCHW at inland stations far from the coasts.

The final residuals $X$ corrected with different OTMs are always similar to each other with differences less than $0.01 \mu$ gal. We cannot decide one OTM is better than all the others before without taking observational errors $\left(E_{\mathrm{ob}}\right)$ into account. Observational errors of each constituent are shown in Fig. 9. The average errors for $O_{1}, K_{1}$, $M_{2}$ and W8 for coastal stations are 0.027, 0.032, 0.043, 0.111 $\mu$ gal, while $0.011,0.015,0.010,0.045 \mu$ gal for middle range stations, and $0.009,0.035,0.009,0.051 \mu$ gal for inland stations. There are only 4 stations where the ratios between the final residuals $X$ and observational errors of each constituent are less than 200\% (2 times of observational RMS) for $O_{1}$, and 4, 1, 3 stations for $K_{1}, M_{2}$, W8. It means that the efficiency of OTL correction is very low for most of the stations, especially at DaLian (DL), Jiu Feng (JF) and Shi Quan Hei $(\mathrm{SQH})$ stations.

In order to consider the observational errors, we calculated the differences between the final residuals $X$ and minimum $X$ while using different OTMs. We only considered difference values higher than 2 times of the uncertainty. The results are shown in Fig. 10. They are different from those for which the observational errors are not taken into account. For coastal stations, SCHW is still the less performant OTM. DTU10, and EOT11a are generally the best OTMs. For the 8 main tidal constituents (W8), DTU10, EOT11a and NAO.99b are the best OTMs for the coastal stations in China. We cannot find a single best OTM for the regions further from the oceans. DTU10 is the best at 12 of the 17 stations based on W8 statistics. Further away, SCHW is the best model for $\mathrm{O}_{1}$ and $\mathrm{K}_{1}$, but worst when considering W8, while FES2014b is just the opposite.

Another factor that should be considered is the calibration of gravimeters. All the gravity meters have been calibrated by the manufacturer. The calibration factors were also controlled by comparison with the SGC0-053 at the Wuhan National Gravity and Earth Tide Observatory before deployment of the gPhones in China.
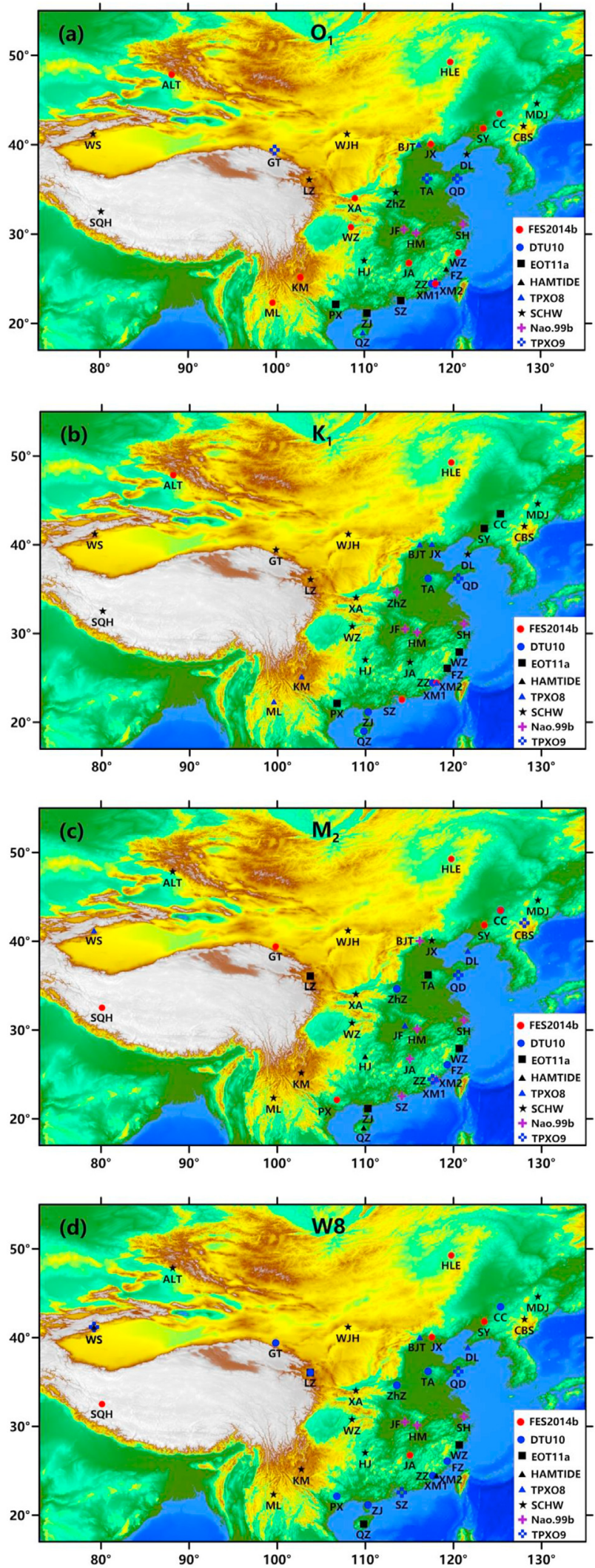

Fig. 8. The distribution of the best OTM: (a) for $O_{1}$; (b) for $K_{1}$; (c) for $M_{2}$; (d) for $W 8$. 


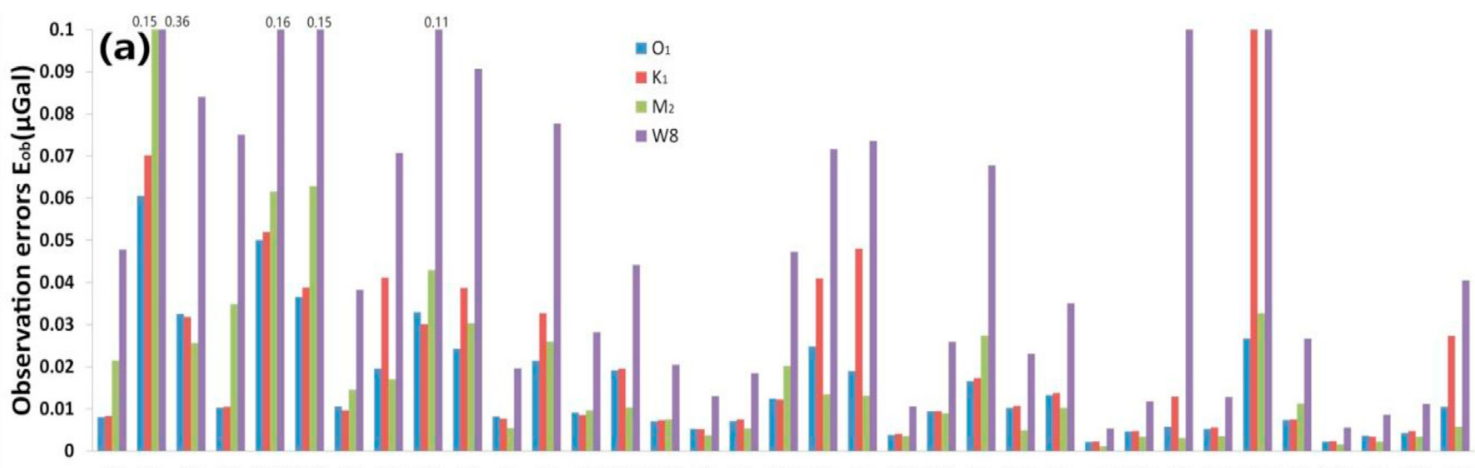

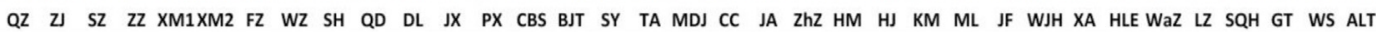

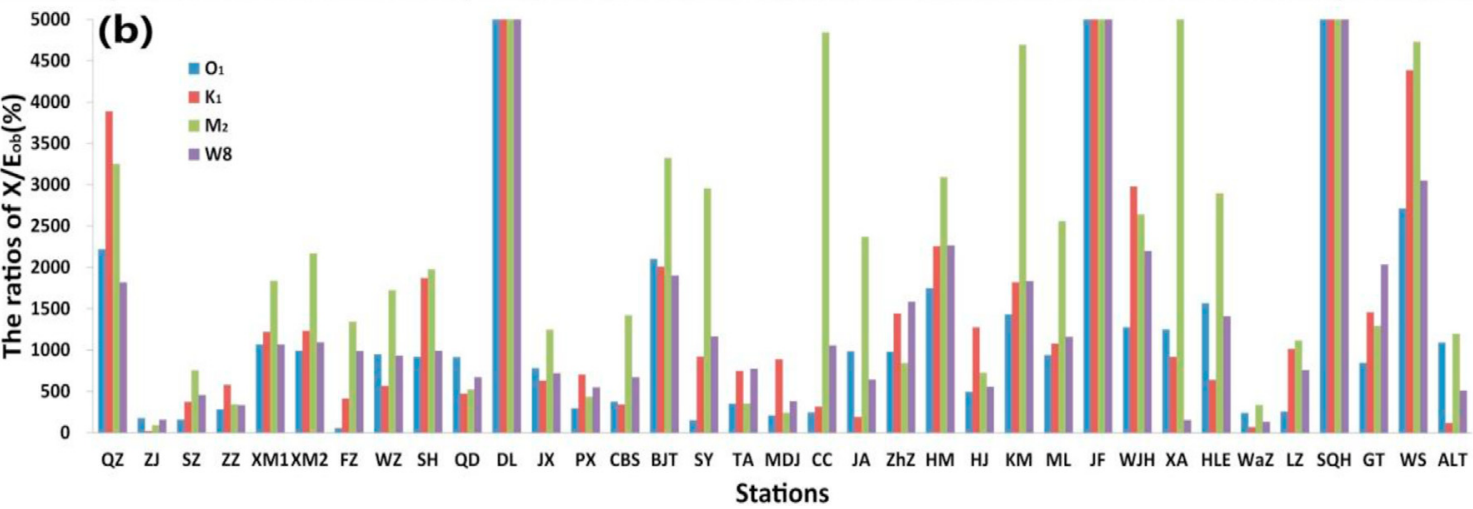

Fig. 9. Observational errors and the ratios of $X / E_{\mathrm{ob}}$ for each constituent.

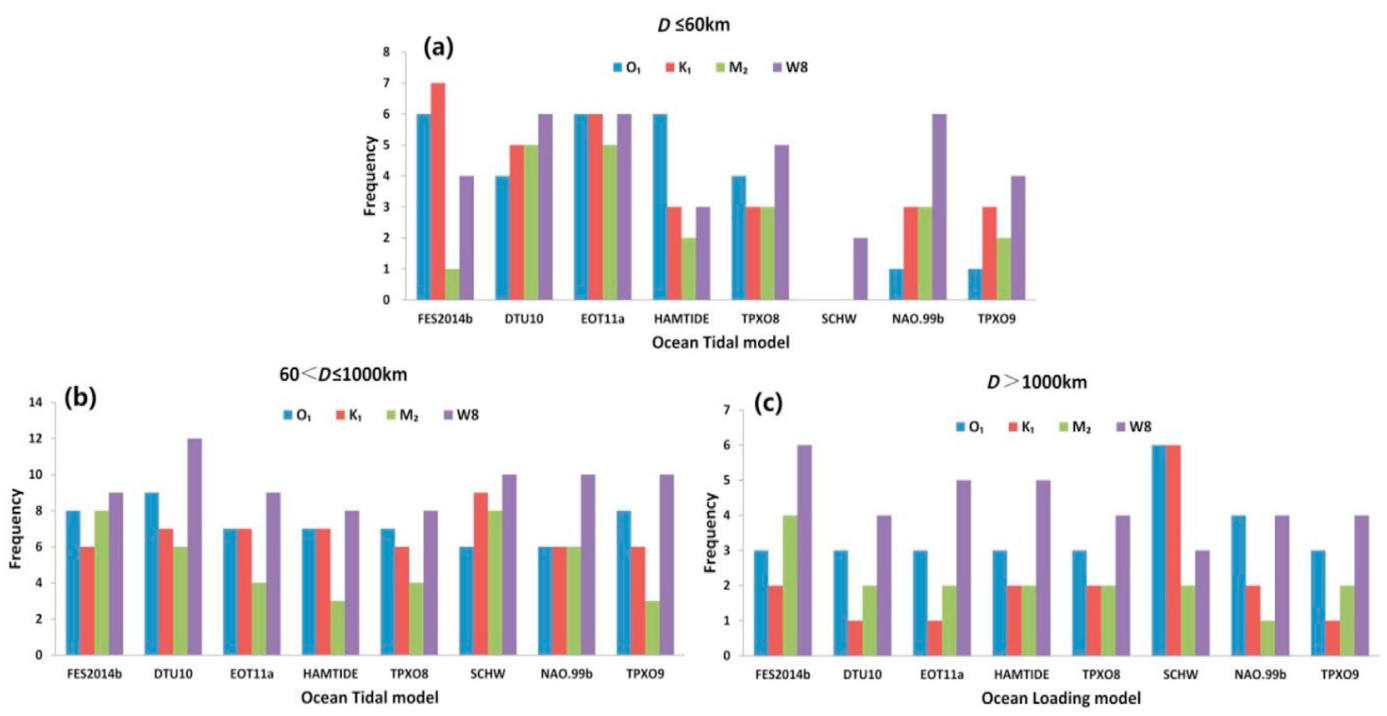

Fig. 10. Statistical results considering two times of observational RMS errors: a) for $D \leq 60 \mathrm{~km}$; b) for $60<D \leq 1000 \mathrm{~km}$; c) for $D>1000 \mathrm{~km}$.

Zhang Rui et al. [24] estimated the calibration factor of the gPhone058 and found a value of $1.0084 \pm 0.0009 \times 10^{-8} \mathrm{~ms}^{-2} / \mathrm{mV}$. Its precision is a few orders of magnitude smaller than the Earth tides including the OTL.

\section{Conclusions}

During this last decade, China initiated an ambitious project of deploying a dense and homogenous tidal gravity network. Most of the stations are equipped with spring relative gPhone gravimeters.
Only 2 stations are equipped with superconducting gravimeters. We use observations from 35 stations and carried out extensive comparisons between observed and calculated ocean tides attraction and loading effects for different OTMs. The outcome of these comparisons is mixed: none of the recent OTMs performs the best for all tidal constituents at every station. Surprisingly, the Schwiderski's model (SCHW), which has already been used for almost 40 years with a coarse resolution of $1^{\circ} \times 1^{\circ}$, is performing relative well with respect to the more recent OTMs. Similar results are obtained in Southeast Asia [25,26]. Dawei Li's [27] result also shows that 
there is about $16 \mathrm{~cm}$ deviation between the global OTMs and Chinese tidal stations. It could be due to systematic errors of the OTM in the Chinese surrounding seas affecting the global OTMs. One way would be effective by inversing the ocean tides in the vicinity of China using gravity data.

\section{Author contributions}

All authors contributed to the study conception and design. Hongbo Tan completed the data processing, counting, analysis and the writing in the paper. Olivier Francis reviewed the paper, provided good suggestions and improved the language. Guiju Wu completed the data processing. Guangliang Yang calculated the OTL. Jiapei Wang analysed data. Xiaotong Zhang provided data and preliminary data processing. Jinshui Huang provided good suggestions. Chongyang Shen revised the abstract, conclusions and reviewed the paper. All authors read and approved the final manuscript.

\section{Conflicts of interest}

The authors declare that there is no conflicts of interest.

\section{Acknowledgments}

We are grateful to the Gravity and Deformation Sub center of China Earthquake Administration Data Sharing Center to provide the gravity data. We also thank to two anonymous reviewers for their comments that improved the manuscript. This research was funded by The National Natural Science Foundation of China (No. 41774015, 41704135 and U1939204) and National Key Research and Development Project of China (No. 2018YFE0206100, 2017YFC1500204).

\section{References}

[1] W.E. Farrell, Deformation of the Earth by surface loads, Rev. Geophys. Space Phys. 10 (3) (1972) 761-797.

[2] H.P. Sun, H.Z. Xu, S.C. Luo, J.Q. Xu, Study of the ocean models using tidal gravity observations, 1155-120, Acta Geod. Cartogr. Sinica 28 (2) (1999) (in Chinese).

[3] O. Francis, Global charts of ocean tide loading effects, J. Geophys.l Res. 95 (C7) (1990) 11411-11424.

[4] Q.P. Wu, Gravity and Earth Tide, Seismological Press, Beijing, China, 1997 (in Chinese).

[5] W. Munkand, D.E. Cartwright, Tidal spectroscopy and prediction, Philos. Trans. R. Soc. London, Ser. A 259 (1966) 533-581.

[6] I.M. Longmen, A Green's function for determining the deformation of the Earth under surface mass loads : 2 Computation and numerical results, J. Geophys. Res. 68 (1963) 485-498.

[7] E.W. Schwiderski, Ocean tides. Part I: global ocean tidal equations, Mar. Geodes. 3 (1980) 161-217.

[8] E.W. Schwiderski, Ocean tides. Part II: a hydrodynamical interpolation model, Mar. Geodes. 3 (1980) 219-255.

[9] F. Lyard, F. Lefevre, T. Letellier, O. Francis, Modelling the global ocean tides: modern insights from FES2004, Ocean Dynam. 56 (2006) 394-415, https:// doi.org/10.1007/s10236-006-0086-x.

[10] L. Carrere, F. Lyard, M. Cancet, A. Guillot, N. Picot, Finite Element Solution FES2014, a New Tidal Model - Validation Results and Perspectives for Improvements, presentation to ESA Living Planet Conference, 2016. Prague.
[11] Y. Cheng, O.B. Andersen, Improvement in global ocean tide model in shallow water regions, OSTST, Lisbon, Poster SV 1-68 (2010) 18-22.

[12] G.D. Egbert, S.Y. Erofeeva, Efficient inverse modeling of barotropic ocean tides, J. Atmos. Ocean. Technol. 19 (2) (2002) 183-204, https://doi.org/10.1175/ 1520-0426(2002)019<0183:EIMOBO>2.0.CO, 2.

[13] R. Savcenko, W. Bosch, EOT11a - a new tide model from Multi-Mission Altimetry, October, OSTST Meeting (2011) 19-21 (San Diego).

[14] E. Taguchi, D. Stammer, W. Zahel, Inferring deep ocean tidal energy dissipation from the global high-resolution data-assimilative HAMTIDE model, J. Geophys. Res. 119 (C7) (2014) 4574-4592, https://doi.org/10.1002/ 2013JC009766.

[15] K. Matsumoto, T. Takanezawa, M. Ooe, ocean tide models developed by assimilating TOPEX/POSEIDON altimeter data into hydrodynamical model: a global model and a regional model around Japan, J. Oceanogr. 56 (2000) 567-581.

[16] C.K. Shum, P. L Woodworth, O.B. Andersen, G.D. Egbert, O. Francis, C. King, S.M. Klosko, C. Le Provost, X. Li, J.M. Molines, M.E. Parke, R.D. Ray, M.G. Schlax, D. Stammer, C.C. Tierney, P. Vincent, C.I. Wunsch, Accuracy assessment of recent ocean tide models, J. Geophys. Res. 102 (C11) (1997) 25173-25194, https://doi.org/10.1029/97JC00445.

[17] G.H. Fang, Y.K. Kwok, K. Yu, Y.H. Zhu, Numerical simulation of principal tidal constituents in the south China sea, Gulf of Tonkin and Gulf of Thailand, Continent. Shelf Res. 19 (7) (1999) 845-869.

[18] X.T. Zhang, Y. Jiang, K. Zhang, X.L. Zhang, The influence of observation environment on background noise level of gPhonegravimeter, Geodesy Geodynam. 8 (6) (2017) 443-447, https://doi.org/10.1016/j.geog.2017.06.002.

[19] P. Vauterin, Tsoft: graphical and interactive software for the analysis of Earth tide data, in: Proc. 13th Int. Sympos. On Earth Tides, Brussels, Observatoire Royal de Belgique, Serie Geophysique, 1998, pp. 481-486.

[20] H.G. Wenzel, The nanogal software: earth tide data preprocessing package ETERNA3.30, Bull. Inf. Marées Terrestres 124 (1996) 9425-9439.

[21] K. Schueller, User's Guide. Manual-02-ET34-ANA-V71, Surin, 2019.

[22] M.S. Bos, H.G. Scherneck, Computation of Green's functions for ocean tide loading, in: G. Xu (Ed.), Sciences of Geodesy -ii, Springer Berlin Heidelberg, 2013, pp. 1-52.

[23] H.G. Scherneck, A parametrized solid Earth tide mode and ocean loading effects for global geodetic base-line measurements, Geophys. J. Int. 106 (3) (1991) 677-694, 1991.

[24] R. Zhang, J. Wei, Z.W. Liu, H. Li, H.T. Hao, gPh058 gravimeter by use of observations with SGC053 superconducting gravimeter, J. Geodesy Geodyn. 31 (5) (2011) 151-155 (in Chinese).

[25] P. Melchior, O. Francis, B. Ducarme, Tidal gravity measurements in Southeast Asia, Marees Terr. Bull. Inf. 125 (1996) 9493-9507.

[26] O. Francis, T. van Dam, Tidal gravity measurements in Southeast Asia revisted, Prog. Geodesy Geodyn. (2014) 338-342. http://orbilu.uni.lu/handle/10993/ 16440.

[27] D.W. Li, J.C. Li, T.Y. Jin, M.Z. Hu, Accuracy estimation of recent global ocean tide models using tide gauge data, J. Geodesy Geodyn. 32 (4) (2012) 106-110 (in Chinese).

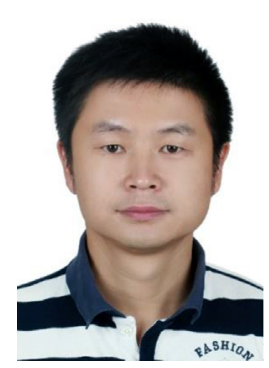

Hongbo Tan, is a PhD student at the University of Science and Technology of China and an associate researcher at the Institute of Seismology, China Earthquake Administration. His research interests include gravity observation, earth tide and seismic dislocation. 